\title{
Thymol Mitigates Monosodium Glutamate-Induced Neurotoxic Cerebral and Hippocampal Injury in Rats through Overexpression of Nuclear Erythroid 2-Related Factor 2 Signaling Pathway as Well as Altering Nuclear Factor-Kappa B and Glial Fibrillary Acidic Protein Expression
}

\author{
Rasha Mostafa $^{1 *(\mathbb{D})}$, Azza Hassan² ${ }^{(\mathbb{D}}$, Abeer Salama $^{1}$ (iD \\ ${ }^{1}$ Department of Pharmacology, Medical Research Division, National Research Centre (ID: 60014618), Dokki, Cairo, Egypt; \\ ${ }^{2}$ Department of Pathology, Faculty of Veterinary Medicine, Cairo University, Giza, Egypt
}

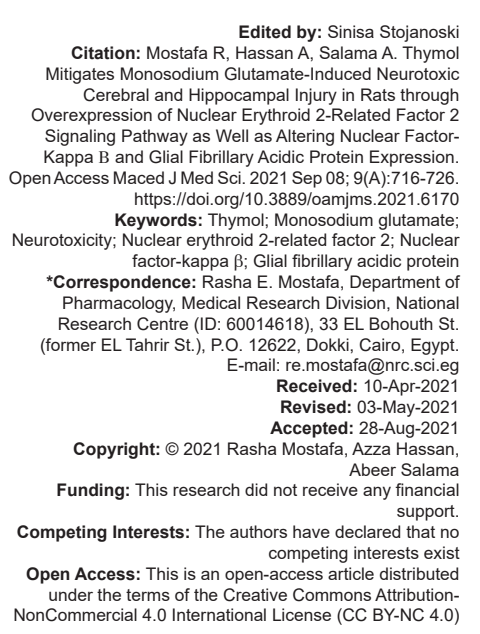

Introduction

Monosodium glutamate (MSG), a salt form of L-glutamic acid, is commonly used in various food industries as a flavor enhancer. MSG is abundant in high concentrations in commercially produced restaurant and household food products [1]. Despite its overspread use, MSG is always suspected to cause many toxic effects, collectively described as "The Chinese restaurant syndrome" [2]. However, many countries pose no strict limitations on the permissible MSG concentrations in food. MSG is described to produce severe metabolic changes, leading to a diverse arena of symptoms including flushing, sweating, weakness, dizziness, headache, and increased oxidative stress in the brain [3].

\begin{abstract}
BACKGROUND: Monosodium glutamate (MSG) is commonly used in various food industries as a flavor enhancer induced neurotoxic cerebral and hippocampal injury in rats. RESULTS: MSG-control group showed a significant reduction in behavioral activity, elevated brain tissue oxidative stress, inflammatory parameters, Nuclear Erythroid 2-Related Factor 2 (Nrf2) gene upregulation, overexpression cortex, and hippocampus. Thymol ameliorated MSG-induced brain injury through overexpression of Nrf2 gene, thus increasing the cellular defense and resulting in organized anti-oxidant and anti-inflammatory effects. Thymo improved behavioral activity and brain tissue glutathione content. Thymol also decreased brain contents of malondialdehyde, nitric oxide, tumor necrosis factor-alpha, and interleukin-6. Moreover, Thymol improved NF-k and GFAP immunohistochemical expression besides histopathological picture in cerebral cortex and hippocampus

the molion: These results suggest that thymol exhibits promising neuroprotective effects. The study elucidates underlying thymol's protection against MSG-induced neurotoxicity. The study also highlights the role of GFAP expression in MSG-induced astrocyte injury of cerebrum and hippocampus of rats and the promising protective effects of thymol in ameliorating astrocyte injury.
\end{abstract} glutamate ions[4]. Ingested glutamate is metabolized in the gastrointestinal tract. As more glutamate is ingested, it gets absorbed through the portal vein. Glutamate is the primary excitatory neurotransmitter in the human brain that plays a crucial role in brain development, synaptic plasticity, and learning. Elevated glutamate concentrations produce abundant neurotoxicity through overactivation of excitatory amino acid receptors. This dilemma increases intracellular calcium, eventually resulting in cellular damage and severe brain excitotoxicity [5].

MSG administration damages the hypothalamic neurons and results in a modification in lipid peroxidation and oxidative stress in various areas of the brain, leading eventually to hyperexcitability and motor as well as behavioral changes [6]. 
Therefore, MSG administration can be considered a reproducible neurotoxic animal model, for testing drug's effects on oxidative stess and neurotoxic cerebral and hippocampal brain injury [7].

Thyme (Thymus vulgaris L.; family Lamiaceae) is a plant native to Mediterranean countries with numerous medicinal and culinary properties [8]. Thymol (2-isopropyl-5-methylphenol) is the main constituent of thyme, contributing to about $10 \%-64 \%$ of its essential oils [9]. Thyme is effective as an antitussive, mucolytic, expectorant, sedative, antihypertensive, antimicrobial, antifungal, diuretic, antispasmodic, neuroprotective agent, and gastroprotective against ulcers [10].

Moreover, many studies proved that thymol improves memory, possesses anticancer [11], antiinflammatory [12] as well as immunomodulatory properties [13]. Most of these effects can be attributed to its antioxidant properties [14]. However, the neuroprotective effects of thymol in neurotoxic cerebral and hippocampal injury have not been well studied.

Therefore, the current study aims at testing the potential molecular mechanisms of the antioxidant and anti-inflammatory effects of thymol against MSGinduced neurotoxic cerebral and hippocampal injury in rats. The study outlines the possible involvement of nuclear erythroid 2-related factor 2 (Nrf2) signaling pathway as well as expression of tumor necrosis factor-alpha (TNF- $\alpha$ ), interleukin-6 (IL-6), and nuclear factor-kappa $\beta$ (NF-k $\beta$ ) in brain tissues. The study also demonstrates the possible protective effects of thymol on the expression of glial fibrillary acidic proteins (GFAP) involved in neuronal damage of brain tissue.

\section{Materials and Methods}

\section{Animals}

Forty adult male Albino Wistar rats weighing $180-200 \mathrm{~g}$ (age $\approx 8-10$ weeks) were used in the current study. Standard food pellets and tap water were supplied ad libitum. Animals and food pellets were obtained from the animal house colony of the National Research Center (NRC, Egypt). The study was conducted in accordance with the NRC-Medical Research Ethics Committee for the use of animal subjects and following the recommendations of the the National Institutes of Health Guide for the care and use of laboratory animals (NIH Publication No. 80-23; revised 1978).

\section{Drugs and chemicals}

MSG (Product \# 1446600) was purchased from Sigma (St. Louis, MO, USA). Thymol fluid extract $\left(\right.$ Thymotal $^{\circledR}$ syrup; each $5 \mathrm{ml}$ contains $1.66 \mathrm{~g}$ standardized to contain $0.03 \%$ phenolic compounds calculated as thymol; ATOS PHARMA, Egypt) was used throughout the study. All other chemicals were of the highest analytical grade available.

\section{Experimental design and treatment protocol}

Animals were randomly allocated into four groups (10 rats each). Rats in Group I received intraperitoneal saline along with distilled water orally for 15 days and served as a normal control group. Brain injury was induced in the remaining three groups by intraperitoneal injection of MSG ( $2 \mathrm{~g} / \mathrm{kg} /$ day) for 15 days. Group II received only distilled water orally for 15 days along with MSG and served as MSG control group. Groups III and IV received thymol (400 and 800 mg/kg/ day; p.o.), respectively, for 15 days. All animals were sacrificed $48 \mathrm{~h}$ after the last drug administration under sodium pentobarbital anesthesia (40 mg/kg; IP).

\section{Methods}

\section{Behavioral tests}

\section{Spontaneous locomotor activity}

The locomotor activity was recorded using an actophotometer (Ugo Basile, Milan, Italy). Actophotometer is a clear acrylic plastic box $(45 \mathrm{~cm} \times$ $45 \mathrm{~cm} \times 45 \mathrm{~cm}$ ) with a removable plastic lid perforated with ventilation holes. The device contains photocell beams and detectors that are mounted on opposite walls. Breaks of the photocell beams detect spontaneous locomotor activity. Before the locomotor task, animals were placed individually in the activity meter cage for 2 min for habituation. After that, locomotor activity was recorded as the counts within 5 min [15].

\section{Rotarod performance test}

Animals were trained to walk on the accelerating rotarod apparatus 2 days before recording the results (Ugo Basile 47600, Milan, Italy). The apparatus consists of a cylinder on which 5 animals can run simultaneously, separated by sufficient size panels to prevent the animals from detecting each other visually. The rod's speed was increased from $4 \mathrm{rpm}$ to $40 \mathrm{rpm}$ during 300s, then the animals were returned to their cages. When the animal could not maintain its balance and fell off the device, it triggered a sensor and the time was recorded [16].

\section{Tissue biochemical analysis}

Rats were sacrificed under sodium pentobarbital anesthesia (40 mg/kg; IP), and their brains were carefully isolated and dissected through the midline into two hemispheres. $0.5 \mathrm{~g}$ of the affected hemisphere was homogenized (using MPW-120 homogenizer, Med instruments, Poland) to obtain $20 \%$ homogenate; the 
homogenate was centrifuged using a cooling centrifuge (Laborezentrifugen, 2k15, Sigma, Germany) at 3000 r.p.m for $10 \mathrm{~min}$; the supernatant was taken for the determination of brain tissue concentrations of lipid peroxidation products malondialdehyde; (MDA), nitric oxide (NO) metabolites and reduced glutathione (GSH) according to the methods adopted by Ruiz-Larrea et al. [17], Miranda et al. [18] and Ellman [19] and modified by Bulaj et al. [20] respectively using commercially available kits (Biodiagnostic, Egypt). Brain tissue contents of TNF- $\alpha$, as well as IL-6 were measured according to the method adopted by Brouckaert et al. [21] using commercially available ELISA kits (SunRed, China).

\section{Real-time polymerase chain reaction (PCR) quantification of Nrf2}

The mRNA expression level of the Nrf2 gene was assessed using real-time PCR standardized by co-amplification with the housekeeping GAPDH gene as an internal control. Nrf2 RNA was extracted from brain tissue using Trizol reagent. RNA was reverse-transcribed using M-MLV reverse transcriptase (Invitrogen, Carlsbad, CA, USA) and then used for PCR with specific primers. Quantification of Nrf2 was carried out using Nrf2 RT-PCR fluorescence diagnostic kit Cat. No. BSA05E3 according to manufactures' instructions (Stratagene, Agilent Biosciences, USA). For amplification, 1 cycle of $95^{\circ} \mathrm{C}$ for $15 \mathrm{~min}$ and then 40 cycles of $94^{\circ} \mathrm{C}$ for $15 \mathrm{~s}, 55^{\circ} \mathrm{C}$ for 25 $\mathrm{s}$, and $72^{\circ} \mathrm{C}$ for $25 \mathrm{~s}$ were performed using Rotor-Gene Q5 plex real-time Rotary analyzer (Corbettlife sciences, USA). The primer sequences are as follows [22].

\begin{tabular}{lll}
\hline Nrf2 & Forward primer & 5'-CAAAAGGAGCAAGAGAAAGCC-3' \\
\multirow{2}{*}{ GAPDH } & Reverse primer & 5'-TCTGATTTGGGAATGTGGGC-3' \\
& Forward primer & 5'-ACCACAGTCCATGCCATCAC-3' \\
& Reverse primer & 5'-TCCACCACCCTGTTGCTGTA-3' \\
\hline
\end{tabular}

\section{Histopathological examination}

Following scarification, the brains were removed and fixed in $10 \%$ neutral formalin for $48 \mathrm{~h}$. Then, the brain tissues were coronally sectioned, washed, dehydrated in alcohol, and embedded in paraffin wax. The sections were cut into $4 \mu \mathrm{m}$ thickness and stained with $\mathrm{H}$ and $\mathrm{E}$ for histopathological examination [23]. For neuronal damage assessment, the number of degenerated and/or necrotic neurons was counted in five random high microscopic power fields (HPF) in both the cerebral cortex and hippocampus of normal and treated groups.

\section{Immunohistochemical analysis of NF-k $\beta$ expression and GFAP}

All the immunohistochemical procedures for the demonstration of NF-k $\beta$ and GFAP expression were performed according to the method of Khalil et al. [24]. Briefly, the paraffin-embedded brain sections were deparaffinized and rehydrated. Then, the sections were incubated with rabbit polyclonal anti-NF-k $\beta$ (ab16502) and anti-GFAP (ab7260) (Abcam) as primary antibodies. Finally, diaminobenzidine (Sigma, USA) was used to visualize the immune reaction. Relying on the percentage of positive cells per HPF, the immune reactivity was semiquantitatively assessed in ten random HPF, according to the method of Hassan et al. (2019), in which; $0=$ no staining, $1=$ positive staining in $<30 \%$ of cells per HPF, $2=$ positive staining in $30-70 \%$ of cells per HPF, or $3=$ positive staining in $>70 \%$ of cells per HPF [25].

\section{Statistical analysis}

All the values are presented as means \pm standard error of the means (SEM). Comparisons between different groups were carried out using one-way analysis of variance (ANOVA) followed by Tukey's multiple comparison post hoc test. Results of histopathological and immunohistochemical assessment were analyzed by Kruskal-Wallis non-parametric ANOVA test followed by Mann-Whitney $U$ test. The difference was considered significant when $p<0.05$. GraphPad prism ${ }^{\circledR}$ software (version 6 for Windows, San Diego, California, USA) was used to carry out these statistical tests.

\section{Results}

\section{Effects of thymol on spontaneous locomotor activity and rotarod rotation time in MSG-induced neurotoxic brain injury in rats}

MSG (2 g/kg; i.p.) resulted in acute brain injury in rats as evidenced by a significant reduction in movement of animals (measured as counts $/ 5 \mathrm{~min}$ ) to $52 \%$ when compared to normal control animals.

While treatment of rats with thymol (400 and $800 \mathrm{mg} / \mathrm{kg} / \mathrm{day}$; p.o) significantly improved the decreased spontaneous locomotor (measured as counts $/ 5 \mathrm{~min}$ ) to $142 \%$ and $177 \%$, respectively, as compared to the MSG control group.

MSG use caused significant reduction in rotarod rotation time of animals (seconds) to $28 \%$ compared to normal control animals.

Thymol treatment (400 and 800 mg/kg/day; p.o) significantly improved the decreased rotarod rotation time (seconds) to $166 \%$ and $226 \%$ respectively as compared to the MSG control group (Table 1).

\section{Effects of thymol on brain tissue oxidative stress parameters in MSG-induced neurotoxic brain injury in rats}

MSG resulted in acute brain injury in rats as evidenced by the significant elevation of brain 
Table 1: Effects of thymol on spontaneous locomotor activity and rotarod rotation time in MSG-induced neurotoxic brain injury in rats

\begin{tabular}{lcc}
\hline Groups & $\begin{array}{c}\text { Spontaneous locomotor } \\
\text { activity (counts } / 5 \mathrm{~min})\end{array}$ & Rotarod rotation time (s) \\
\hline Normal control & $133.40 \pm 7.49$ & $419.80 \pm 20.11$ \\
MSG control & $68.83 \mathrm{a} \pm 4.07$ & $117.00^{\mathrm{a}} \pm 12.12$ \\
$(2 \mathrm{~g} / \mathrm{kg}$; i.p.) & $97.40^{\mathrm{a}, \mathrm{b}} \pm 3.46$ & $194.00^{\mathrm{a}, \mathrm{b}} \pm 11.03$ \\
$\begin{array}{l}\text { MSG + Thymol } \\
(400 \mathrm{mg} / \mathrm{kg} / \text { day; } \text { p.o. })\end{array}$ & $122.00^{\mathrm{b}} \pm 9.22$ & $265.00^{\mathrm{a}, \mathrm{b}} \pm 18.71$ \\
MSG + Thymol & & \\
$(800 \mathrm{mg} / \mathrm{kg} /$ day; p.o. $)$ &
\end{tabular}

Rats of the normal control group (Group I) received intraperitoneal saline. Brain injury was induced in theremaining 3 groups by intraperitoneal injection of MSG $(2 \mathrm{~g} / \mathrm{kg}$; i.p.) for 15 days. Group II received only distilled water orally along with MSG and served as MSG control group. Groups III and IV received thymo (400 and $800 \mathrm{mg} / \mathrm{kg}$ day; 0.$)$ respectively for 15 days. Spontan (400 and $800 \mathrm{mg} / \mathrm{kg} / \mathrm{day}$, p.o.) respectively for 15 days. Spontaneous locomotor activity and rotarod rotation

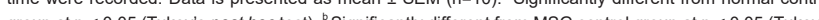
group at $p<0.05$ (Tukey's post hoc test). 'Significantly different from MSG control group at $p<0.05$ (Tukey's
post hoc test).MSG: Monosodium glutamate.

tissue concentration of MDA and NO to $273 \%$ and $201 \%$, respectively, and the significant reduction of GSH to $27 \%$ as compared to the normal control group.

Treatment of rats with thymol (400 and $800 \mathrm{mg} / \mathrm{kg} / \mathrm{day} ; \quad$ p.o) significantly decreased the elevated brain tissue concentration of MDA to $79 \%$ and $53 \%$. Thymol treatment decreased the elevated brain tissue concentration of $\mathrm{NO}$ to $79 \%$ and $63 \%$. Moreover, thymol treatment elevated brain tissue GSH concentration to $156 \%$ and $233 \%$, respectively, when compared to the MSG control group (Table 2).

Table 2: Effects of thymol on brain tissue concentration of lipid peroxidation products (MDA), NO metabolites and GSH in MSG-induced neurotoxic brain injury in rats

\begin{tabular}{lccc}
\hline Groups & $\begin{array}{c}\text { MDA } \\
(\mu \mathrm{mol} / \mathrm{g} \text { wet tissue })\end{array}$ & $\begin{array}{c}\text { NO } \\
(\mu \mathrm{mol} / \mathrm{g} \text { wet tissue })\end{array}$ & $\begin{array}{c}\text { GSH } \\
(\mu \mathrm{mol} / \mathrm{g} \text { wet tissue })\end{array}$ \\
\hline $\begin{array}{l}\text { Normal control } \\
\text { MSG control }\end{array}$ & $122.02 \pm 5.70$ & $56.34 \pm 3.78$ & $8.42 \pm 0.28$ \\
$(2 \mathrm{~g} / \mathrm{kg}$; i.p. $)$ & & $113.30^{\mathrm{a}} \pm 5.50$ & $2.27^{\mathrm{a}} \pm 0.29$ \\
MSG + Thymol & $262.44^{\mathrm{a}, \mathrm{b}} \pm 14.19$ & $89.34^{\mathrm{a}, \mathrm{b}} \pm 3.21$ & $3.54^{\mathrm{a}, \mathrm{b}} \pm 0.18$ \\
$\begin{array}{l}(400 \mathrm{mg} / \mathrm{kg} / \text { day; } \text { p.o. }) \\
\text { MSG + Thymol }\end{array}$ & $178.24^{\mathrm{a}, \mathrm{b}} \pm 5.74$ & $71.22^{\mathrm{b}} \pm 2.25$ & $5.28^{\mathrm{a}, \mathrm{b}} \pm 0.19$ \\
(800 mg/kg/day; p.o.) & & &
\end{tabular}

Rats of the normal control group (Group I) received intraperitoneal saline. Brain injury was induced in theremaining 3 groups by intraperitoneal injection of MSG $(2 \mathrm{~g} / \mathrm{kg}$; i.p.) for 15 days. Group II received only distilled water olly along with MSG and served as MSG control group. Groups III and IV recived thym (400 and 800 mg thymol (400 and $800 \mathrm{mg} / \mathrm{kg} / \mathrm{day} ;$ p.o.) respectively for 15 days. All animals were sacriced $48 \mathrm{~h}$ atter the last drug administration, the brains were dissected out, homogenized and the homogenate was 0 blained. Data is prosentod as mean \pm SEM ( $n=10$ ). Signifcantly different from norm $p<0.05$ (Tukey's post hoc test). 'Significantly different from MSG control group at $p<0.05$ (Tukey's pos hoc test). MSG: Monosodium glutamate, MDA: Malondialdehyde, NO: Nitric oxide, GSH: Glutathione.

\section{Effects of thymol on brain tissue} concentration of TNF- $\alpha$ and IL-6 in MSG-induced neurotoxic brain injury in rats

Acute brain injury in rats induced by MSG resulted in a significant elevation of brain tissue concentration of TNF- $\alpha$ and IL-6 to $393 \%$ and $432 \%$, respectively, as compared to the normal control group.

Thymol treatment $(400$ and $800 \mathrm{mg} / \mathrm{kg} /$ day; p.o) significantly reduced the elevated brain tissue concentration of TNF- $\alpha$ to $68 \%$ and $36 \%$. Thymol treatment also reduced the elevated brain tissue concentration of IL-6 to $60 \%$ and $38 \%$, respectively, as compared to the MSG control group (Figure 1).

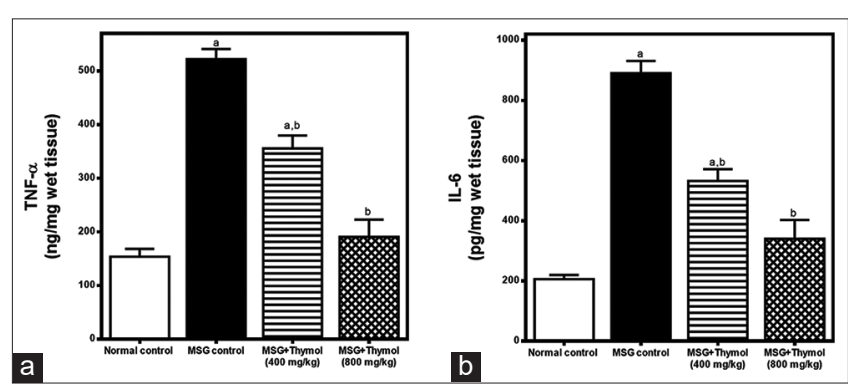

Figure 1: Effects of thymol on brain tissue concentration of (a) Tumor necrosis factor- $\alpha$ and (b) Interleukin- 6 in monosodium glutamateinduced neurotoxic brain injury in rats. Rats of the normal control group (Group I) received intraperitoneal saline. Brain injury was induced in theremaining 3 groups by intraperitoneal injection of MSG (2 g/kg; i.p.) for 15 days. Group II received only distilled water orally along with MSG and served as MSG control group. Groups III and IV received thymol (400 and $800 \mathrm{mg} / \mathrm{kg} /$ day; p.o.) respectively for 15 days. All animals were sacrificed $48 \mathrm{~h}$ after the last drug administration, the brains were dissected out, homogenized and the homogenate was obtained. Data is presented as mean \pm SEM $(n=10)$. ${ }^{a}$ Significantly different from normal control group at $p<0.05$ (Tukey's post hoc test). ${ }^{b}$ Significantly different from MSG control group at $p<0.05$ (Tukey's post hoc test)

\section{Quantitative RT-PCR for Nrf2 gene expression in brain tissue}

The expression response of Nrf2 gene in rat brains following MSG-induced oxidative stress and neurotoxic brain injury was analyzed using qRT-PCR. Nrf2 was upregulated in MSG-control group to reach 1.15 -fold as compared to the normal control group.

Treatment of rats with thymol (400 and $800 \mathrm{mg} / \mathrm{kg} /$ day; p.o) significantly overexpressed the Nrf2 gene in brain tissue to 1.32-fold and 2.02-fold respectively as compared to the MSG control group (Figure 2).

\section{Histopathological examination of cerebral cortex and hippocampus}

The result of histopathological assessment of neuronal damage is illustrated in Table 3. Brains of normal rats showed normal histological structure with normal rounded cerebral cortical and hippocampal neurons (Figures $3 a$ and b, respectively). Meanwhile, pronounced neuronal damage was demonstrated in the brains of MSG-treated rats. This damage was manifested by the presence of shrunken eosinophilic necrotic neurons associated with neuronophagia

Table 3: The number of degenerated and/or necrotic neurons recoded in the cerebral cortex and hippocampus of normal and treated rats

\begin{tabular}{|c|c|c|}
\hline \multirow[t]{2}{*}{ Groups } & \multicolumn{2}{|c|}{$\begin{array}{l}\text { Number of degenerated and/or necrotic neurons } \\
\text { (NO/HPF) }\end{array}$} \\
\hline & Cerebral cortex & Hippocampus \\
\hline Normal control & $0.20^{\mathrm{a}} \pm 0.20$ & $0.40^{\mathrm{a}} \pm 0.24$ \\
\hline $\begin{array}{l}\text { MSG control } \\
(2 \mathrm{~g} / \mathrm{kg} \text {; i.p.) }\end{array}$ & $16.20^{b} \pm 1.28$ & $11.80^{b} \pm 1.06$ \\
\hline $\begin{array}{l}\text { MSG + Thymol } \\
\text { (400 mg/kg/day; p.o.) }\end{array}$ & $9.60^{c} \pm 1.77$ & $5.00^{\mathrm{c}} \pm 0.83$ \\
\hline $\begin{array}{l}\text { MSG + Thymol } \\
(800 \text { mg/kg/day; p.o.) }\end{array}$ & $4.40^{d} \pm 2.30$ & $3.40^{d} \pm 0.60$ \\
\hline
\end{tabular}


and diffuse proliferation of microglia cells and astrocytes that are characteristically demonstrated in the cerebral cortex (Figure 3c) and hippocampus (Figure 3d) of this group. Treatment with thymol remarkably ameliorates these histopathological alterations in a dose-dependent manner. Decreased

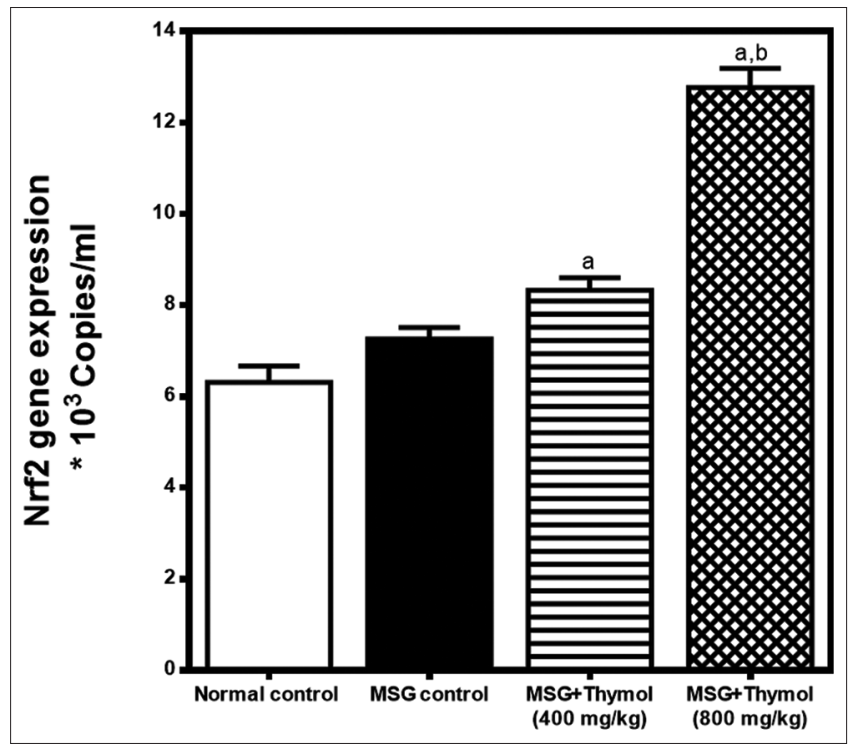

Figure 2: Real-time polymerase chain reaction quantitation of $m R N A$ expression level of Nrf2 gene in brain tissue in monosodium glutamate (MSG)-induced neurotoxic brain injury in rats. Rats of the normal control group (Group I) received intraperitoneal saline. Brain injury was induced in there maining 3 groups by intraperitoneal injection of MSG (2 g/kg; i.p.) for 15 days. Group II received only distilled water orally along with MSG and served as MSG control group. Groups III and IV received thymol (400 and $800 \mathrm{mg} / \mathrm{kg} /$ day; p.o.) respectively for 15 days. All animals were sacrificed $48 \mathrm{~h}$ after the last drug administration, the brains were dissected out, homogenized and the homogenate was obtained. Data is presented as mean \pm SEM $(n=10)$. ' Significantly different from normal control group at $p<$ 0.05 (Tukey's post hoc test). ${ }^{b}$ Significantly different from MSG control group at $p<0.05$ (Tukey's post hoc test) number of degenerated and/or necrotic neurons and moderate gliosis were observed in the cerebral cortex and hippocampus of MSG-Thymol (400 mg/ $\mathrm{kg}$ ) group (Figure $3 \mathrm{e}$ and $\mathrm{f}$, respectively). On the other side, minimal neuronal damage and gliosis were demonstrated in MSG-Thymol (800 mg/kg) group, in which most of cerebral cortical and hippocampal neurons appeared normal with scant degenerated ones (Figure $3 g$ and $h$, respectively).

\section{Immunohistochemical analysis of NF-k $\beta$ expression in cerebral cortex and hippocampus}

The results of immunohistochemical analysis of NF-k $\beta$ expression in cerebral cortex and hippocampus are illustrated in Table 4. Brains of normal rats showed normal cytoplasmic staining of neurons of both cerebral cortex (Figure 4a) and hippocampus (Figure 4b) with no evidence of nuclear translocation. On the contrary, significant increase of NF-k $\beta$ expression, which was demonstrated mainly in the nuclei of cerebral cortical neurons (Figure 4c) and pyramidal cells of hippocampus (Figure 4d). Conversely, the percentage of NF-k $\beta$ positively stained cells were significantly reduced in the cerebral cortex (Figure 4e) and hippocampus (Figure 4f)

Table 4: The results of NF-k $\beta$ expression recorded in the cerebral cortex and hippocampus of normal and treated rats

\begin{tabular}{lll}
\hline Groups & \multicolumn{2}{l}{ NF-k $\beta$ expression (\%of positive cells/HPF) } \\
\cline { 2 - 3 } & Cerebral cortex & Hippocampus \\
\hline Normal control & $0.10^{\mathrm{a}} \pm 0.10$ & $0.20^{\mathrm{a}} \pm 0.13$ \\
MSG control & $2.70^{\mathrm{b}} \pm 0.15$ & $2.30^{\mathrm{b}} \pm 0.15$ \\
$(2 \mathrm{~g} / \mathrm{kg}$; i.p.) & & \\
MSG + Thymol & $2.10 \mathrm{c} \pm 0.27$ & $1.20^{\mathrm{c}} \pm 0.20$ \\
( $400 \mathrm{mg} / \mathrm{kg} /$ day; p.o.) & & \\
MSG + Thymol & $1.30^{\mathrm{d}} \pm 0.15$ & $1.10^{\mathrm{d}} \pm 0.10$
\end{tabular}

$(800 \mathrm{mg} / \mathrm{kg} /$ day; p.o.)

Different lowercase letters are significantly different $(\mathfrak{p}<0.05)$. MSG: Monosodium glutamate,

NF-k $\beta$ : Nuclear factor-kappa $\beta$

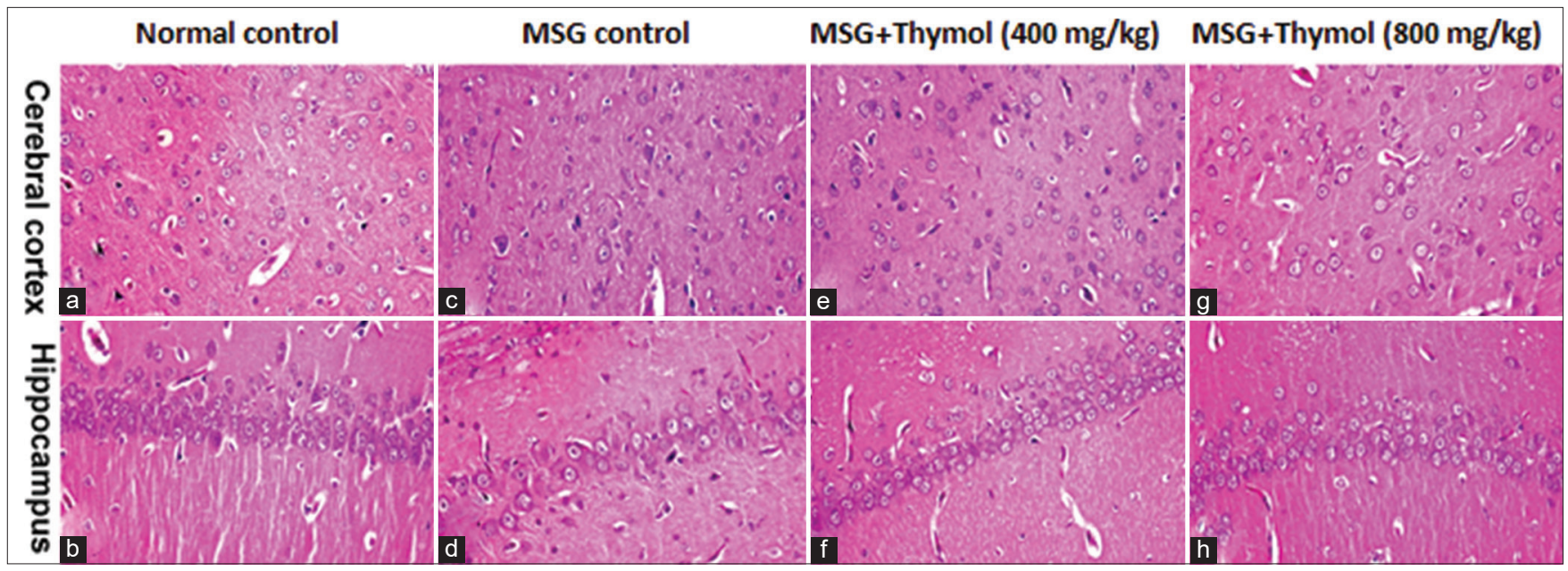

Figure 3: Histopathological examination of cerebral cortex and hippocampus. Brain tissues, stained with $\mathrm{H}$ and $\mathrm{E}$, of (a and b) normal rats showing normal rounded neurons of cerebral cortex (a) and hippocampus (b); (c and d) MSG-treated rats showing shrunken eosinophilic necrotic neurons (short arrow) associated with neuronophagia (long arrow) (and diffuse proliferation astrocytes (dashed arrow) in the cerebral cortex (c) and hippocampus (d); (e and f) MSG-Thymol (400 mg/kg b.w.)-treated rats showing decreased number of degenerated and/ or necrotic neurons in the cerebral cortex (e) and hippocampus (f); ( $g$ and h) MSG-Thymol (800 mg/kg b.w.)-treated rats showing scant degenerated neurons in the cerebral cortex (g) and normal hippocampus (h). (Stain: H and E, ×40) 
of MSG-Thymol $(400 \mathrm{mg} / \mathrm{kg})$ group, in which most neurons showed cytoplasmic staining. Pronounced reduction of NF-k $\beta$ expression, with minimal nuclear staining was demonstrated in the cerebral cortex (Figure $4 \mathrm{~g}$ ) and hippocampus (Figure 4h) of MSGThymol (800mg/kg) group.

\section{Immunohistochemical analysis of GFAP expression in cerebral cortex and hippocampus}

The results of immunohistochemical analysis of GFAP expression in cerebral cortex and hippocampus are illustrated in Table 5. Few weakly stained astrocytes with small cell bodies and short cytoplasmic processes were demonstrated in the cerebral cortex (Figure 5a) and hippocampus (Figure $5 \mathrm{~b}$ ) of normal rats. Whereas, significant increase of percentage of GFAP+ astrocytes with large hypertrophied cell bodies and thicker as well as longer cytoplasmic processes recorded in the cerebral cortex (Figure 5c) and hippocampus (Figure 5d) of MSG-treated rats. On the other hand, the percentage of GFAP+ astrocytes was significantly decreased in thyme-treated groups in a dose dependent

Table 5: The results of glial fibrillary acidic proteins expression recorded in the cerebral cortex and hippocampus of normal and treated rats

\begin{tabular}{lll}
\hline Groups & \multicolumn{2}{l}{$\begin{array}{l}\text { Glial fibrillary acidic proteins expression (\%of } \\
\text { positive cells/HPF) }\end{array}$} \\
\cline { 2 - 3 } & Cerebral cortex & Hippocampus \\
\hline Normal control & $1.20^{\mathrm{a}} \pm 0.13$ & $1.10^{\mathrm{a}} \pm 0.10$ \\
MSG control & $2.80^{\mathrm{b}} \pm 0.13$ & $2.90^{\mathrm{b}} \pm 0.10$ \\
$(2 \mathrm{~g} / \mathrm{kg}$; i.p.) & $1.90^{\mathrm{c}} \pm 0.17$ & $1.90^{\mathrm{c}} \pm 0.17$ \\
MSG + Thymol & $1.60^{\mathrm{a}, \mathrm{c}} \pm 0.16$ & $1.40^{\mathrm{a}} \pm 0.16$ \\
$\begin{array}{l}\text { (400 mg/kg/day; p.o.) } \\
\text { MSG + Thymol }\end{array}$ & & \\
\hline (800 mg/kg/day; p.o.) & &
\end{tabular}

manner. Few GFAP+ astrocytes with hypertrophied cell bodies were demonstrated in the cerebral cortex of MSG-Thymol (400 mg/kg) group (Figure 5e). But these cells were much hypertrophied in the hippocampus of this group (Figure 5f). Significant reduction of GFAP+ astrocytes, which appeared in focal aggregate, was demonstrated in the cerebral cortex and hippocampus of MSG-Thymol (800mg/kg) group (Figures $5 \mathrm{~g}$ and $3 \mathrm{~h}$, respectively).

\section{Discussion}

MSG is commonly used in various food industries as a flavor enhancer. MSG is reported to produce severe metabolic changes, leading to abundant neurotoxicity and motor as well as behavioral changes [5]. Therefore, the current study aims at scouting the potential underlying molecular mechanisms involved in MSG-induced neurotoxic brain injury in rats. This study is the first to evaluate the role of the Nrf2 signaling pathway as well as NF-k $\beta$ and GFAP expression in MSG-induced brain injury and the potential neuroprotective antioxidant and anti-inflammatory effects of thymol on MSG-induced neurotoxic cerebral and hippocampal injury in rats.

In the current study, MSG administration resulted in a significant alteration in motor and behavioral activities in rats as manifested by a reduction of the spontaneous locomotor activity as well as the rotarod rotation time of rats. This data agrees with Shivasharan et al., who stated that MSG significantly decreased the locomotor activity of adult female Wistar rats [7].

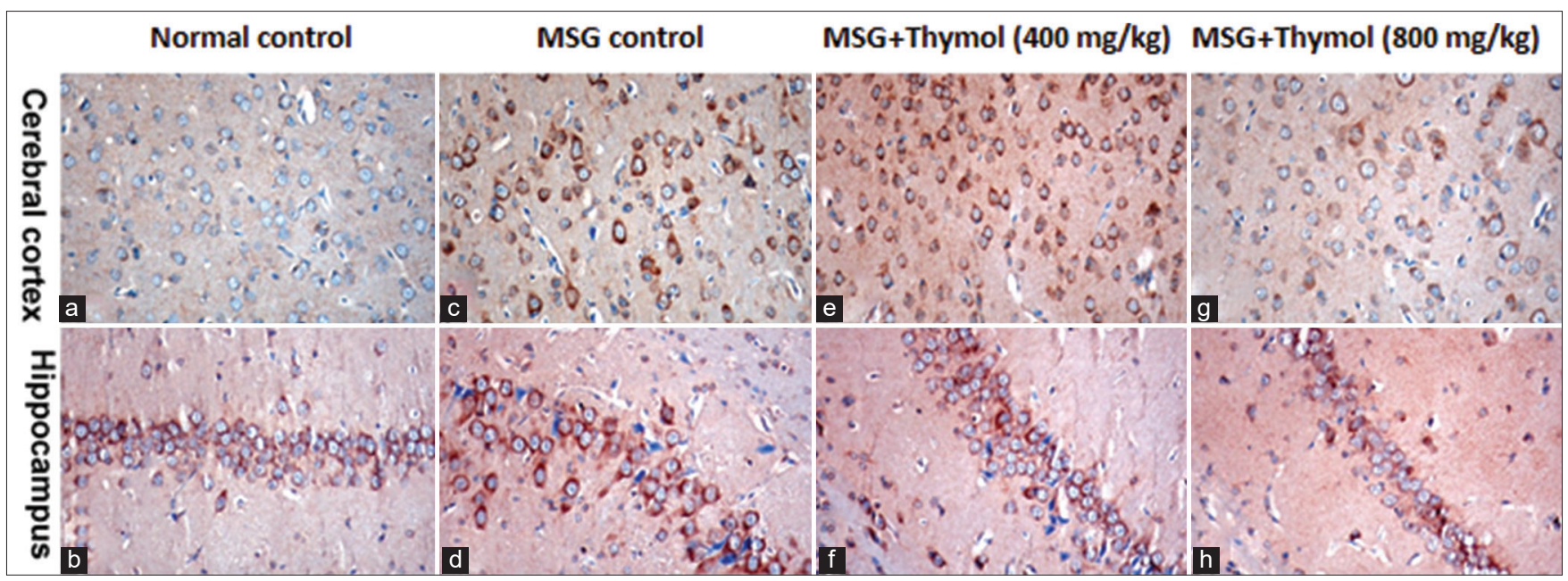

Figure 4: Immunohistochemical analysis of nuclear factor-kappa $\beta$ (NF-kß) expression in cerebral cortex and hippocampus. Brain tissues, immunohistochemically stained with NF-kB, of ( $a$ and $b$ ) normal rats showing normal cytoplasmic staining of neurons of both cerebral cortex (a) and hippocampus (b); ( $c$ and d) Monosodium glutamate (MSG)-treated rats showing significant increase of NF-k 3 expression in the nuclei of cerebral cortical neurons (c) and pyramidal cells of hippocampus (d); (e and f) MSG-Thymol (400mg/kg)-treated rats showing decreased

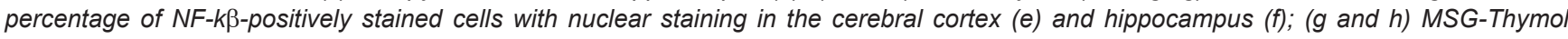
$(800 \mathrm{mg} / \mathrm{kg})$-treated rats showing pronounced reduction of NF-k $\beta$ expression, with minimal nuclear staining in the cerebral cortex (g) and hippocampus (h). (NF-kß immunohistochemical staining, $\times 40$ ) 


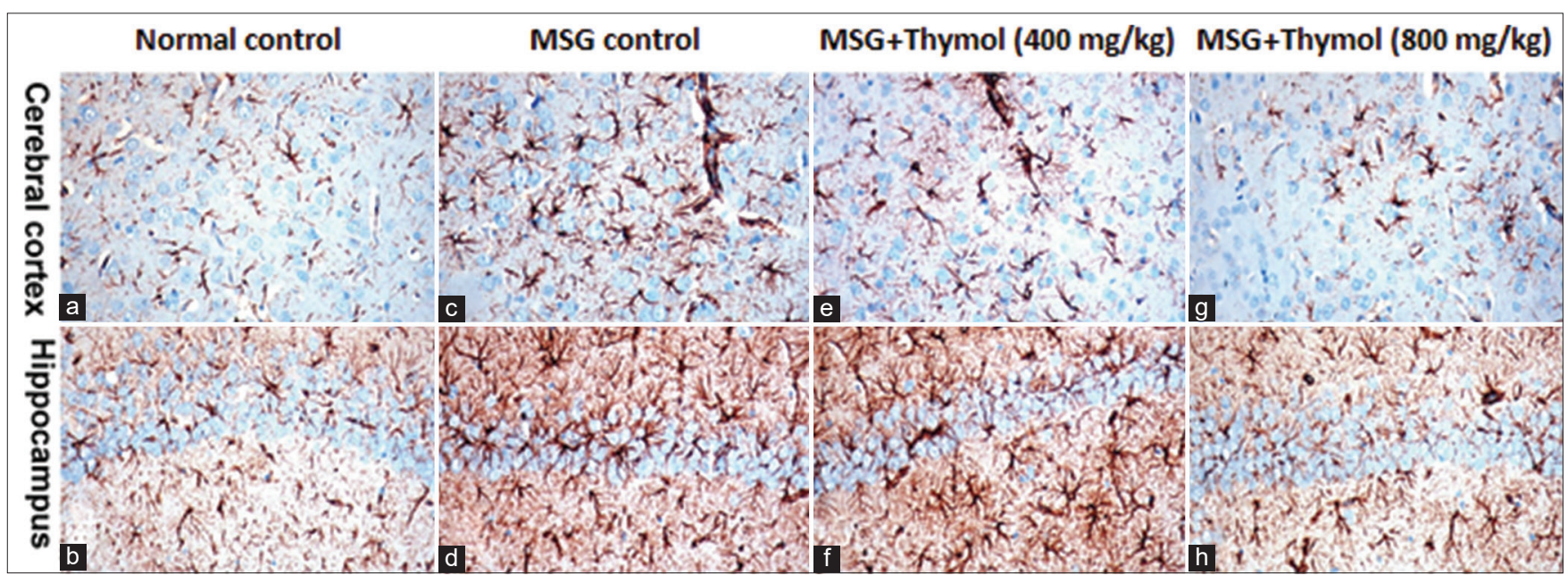

Figure 5: Immunohistochemical analysis of glial fibrillary acidic proteins (GFAP) expression in cerebral cortex and hippocampus. Brain tissues, immunohistochemically stained with GFAP, of ( $a$ and b) normal rats showing few weakly stained astrocytes with small cell bodies and short cytoplasmic processes in the cerebral cortex (a) and hippocampus (b); (c and d) Monosodium glutamate (MSG)-treated rats showing increased GFAP+ astrocytes with large hypertrophied cell bodies and thicker as well as longer cytoplasmic processes in the cerebral cortex (c) and hippocampus (d); (e and f) MSG-Thymol (400mg/kg)-treated rats showing few GFAP+ astrocytes with hypertrophied cell bodies in the cerebral cortex (e) and much hypertrophied GFAP+ astrocytes in the hippocampus (f); ( $g$ and $h$ ) MSG-Thymol (800mg/kg)-treated rats showing decreased percentage of GFAP+ astrocytes in the cerebral cortex (g) and hippocampus (h) (GFAP immunohistochemical staining, $\times 40$ )

Swamy et al. also demonstrated that MSG caused a significant reduction in spontaneous locomotor activity in Wistar albino rats [26].

MSG administration also resulted in a significant elevation of lipid peroxidation products and $\mathrm{NO}$ metabolites with a substantial reduction in $\mathrm{GSH}$ concentration in rats' brain tissue compared to the normal group; indicating severe oxidative damage to brain tissues. Many studies agree with this data demonstrating alteration in brain tissues antioxidative defense mechanisms post-MSG administration [1], [27].

In the current work, MSG administration resulted in a significant elevation of brain tissue concentration of IL-6 and TNF- $\alpha$ compared to the normal group; indicating significant inflammatory damage of brain tissue. Khalil and Khedr stated that MSG administration resulted in a significant inflammatory response to brain tissue as manifested by an elevation of TNF- $\alpha$ in the hippocampus of MSG-treated rats [28].

In the current work, Nrf2 was up-regulated in the MSG-control group as compared to the normal control group. In the basal non-stressed condition, Nrf2 is primarily abundant in the cytoplasm bound to the cytoplasmic Kelch-like ECH associated protein 1(Keapl). Binding to Keap1 blocks Nrf2 activation to keep Nrf2 concentration low. In case of occurrence of any endogenous or exogenous cellular events mandating cellular defense mechanisms, abrupt induction of Nrf2 occurs. Oxidative stress and/or inflammation decouple Keap1 from Nrf2 to activate the latter along with a further synthesis of Nrf2. Nrf2 is then transferred into the nucleus to bind with antioxidant response elements (ARE); also known as electrophile response elements. This binding further activates Nrf2/ARE pathway. Nrf2 activation eventually results in an organized antioxidant, anti-inflammatory and anti-apoptotic responses in vivo [29]. Nrf2 gene overexpression also stimulates protective proteins such as; the brain-derived neurotrophic factor, peroxisome proliferator-activated receptor gamma co-activator $1 \alpha$ and the auto-phagic protein p62. External causes can induce Nrf2 activation, and it has been linked to many endogenous pathophysiological defense mechanisms in numerous systems, including the cardiovascular and the nervous systems [30]. It has been confirmed that the Nrf2 pathway plays a crucial role in CNS, in the case of brain inflammation, acute cerebral injuries as well as neurodegenerative disorders [31]. Besides, a significant increase of NF-k $\beta$ expression, in the current work, was demonstrated in the nuclei of cerebral cortical neurons and pyramidal cells of the hippocampus of the MSG-control group. NF-k $\beta$ is found to suppress the transcription of ARE-dependent genes, and thus it acts as a crucial regulator of inflammation. $\mathrm{NF}-\mathrm{k} \beta$ is inactivated in the cytoplasm via binding to an inhibitor of NF-k $\beta$-kinase subunit beta. The molecular mechanisms linking NF-k $\beta$ and Nrf2 are not yet welldefined. However, the Nrf2 gene contains binding sites for NF-k $\beta$ in the promoter region which proposes a possible inter-relation between these two inflammatory regulators [32]. In line with our findings, many studies reported over-expression of Nrf2 as well as NF-k $\beta$ in different experimental animal models of brain injury. Li et al., Zhang et al. and Cheng et al. reported overexpression of Nrf2 signaling in experimental traumatic brain injury [33], [34], [35]. Wei et al. reported activation of the Nrf2 signaling pathway post-intracerebral hemorrhage [36]. Du et al. reported up-regulation of Keap1/Nrf2 pathway in MSG-induced obese cardiomyopathy [37]. Xu et al. reported overexpression of NF-k $\beta$ pathway in neuro-inflammation in rats following subarachnoid hemorrhage [38]. In line with this data, 
Nurmasitoh et al. reported that NF-k $\beta$ reduction results in antioxidant and anti-inflammatory effects [39]. The current study showed a significant histopathological injury of the brains of MSG-treated rats as manifested by the presence of shrunken necrotic neurons and proliferation of microglia cells and astrocytes in the cerebral cortex and hippocampus. Many studies reported severe alteration in brain tissue histopathological picture following MSG administration. Shivasharan et al. reported the appearance of numerous shrunken cells in the hippocampus of MSG-treated rats [7]. Onaolapo et al. reported significant degenerative cerebrum changes of MSG-treated mice accompanied by loss of the cerebellar architecture, vacuolation, and loss of the Purkinje cell monolayer. They also reported distortion of normal hippocampal architecture, mild edema and abundance of degenerating pyramidal cells as well as distorted cellular morphology in the hippocampal region of MSG-treated mice [1]. Swamy et al. reported severe alterations in brains of MSG-treated rats as was apparent by cerebral edema, pyknosis, eosinophilia and karyorrhexis [26]. MSG was reported to cause severe histopathological alterations of the cerebrum, cerebellum and hippocampus of treated experimental animals [6].

Astrocytes makeup about $50 \%$ of the brain tissue and are essential for the normal physiology and survival of the neurons. GFAP is a crucial protein secreted by mature astrocytes. GFAP is an astrocyte-specific marker that controls astrocytes' shape and movement. GFAP expression is an immunohistochemical marker for reactive astrocytes. GFAP is overexpressed in response to neuronal damage, especially synaptic efficacy [40]. The current study demonstrates a significant increase in the percentage of GFAP astrocytes with large hypertrophied cell bodies and thicker as well as longer cytoplasmic processes recorded in the cerebral cortex and hippocampus of MSG-treated rats. In line with this finding, Zaher reported significant histopathological alterations and severe GFAP immunoreactivity in the hippocampus of MSG-treated rats [41]. Hashem et al. also described histological distortment accompanied by moderate GFAP immunohistochemical expression in the astrocytes of cytoplasm as well as a granular layer of the cerebellar cortex of MSG-treated rats [40].

The current study aimed to test the protective effects of thymol against MSG-induced neuro-toxic cerebral and hippocampal injury in rats, emphasizing the potential molecular mechanisms underlying this neuroprotection.

In the current work, thymol in the selected doses improved behavioral changes caused by MSG administration. This was manifested by an improvement of the decreased spontaneous locomotor and rotarod rotation time compared to the MSG control group.

Thymol has been reported to be a positive activator of the GABAA receptors in humans [42]. This may account for its neuroprotective effects, especially in the case of MSG-induced neurotoxicity. MSG dissociates in the body to yield glutamate ions producing abundant neuro-toxicity via over-activation of excitatory amino acid receptors. Sancheti et al. stated that thymol administration resulted in anti-epileptogenic activity in rats, manifested by improved locomotor activity and seizure score [43].

According to previous studies, thymol improved oxidative stress parameters by decreasing MDA and $\mathrm{NO}$ metabolites and increasing GSH concentration in brain tissues compared to the MSG control group. This can be attributed to thymol's antioxidative properties. Moreover, thymol administration resulted in a significant reduction of elevated IL- 6 and TNF- $\alpha$ concentration in brain tissues as compared to the MSG-treated group. This can be attributable to thymol's potential antiinflammatory properties. The anti-inflammatory effects of thymol also account for the significant reduction of NF-k $\beta$ immunohistochemical expression in the cerebral cortex and hippocampus of rats as compared to MSGtreated rats. Interestingly, thymol administration also resulted in considerable overexpression of the Nrf2 gene in brain tissue compared to the MSG control group. This indicates activation of the theNrf2 signaling pathway, which results in organized antioxidant, anti-inflammatory, anti-apoptotic actions. Thymol also improved the overall histopathological pictures of the cerebral cortex and hippocampus of rats. Moreover, thymol significantly decreased GFAP expression in the cerebral cortex and hippocampus compared to the MSG group.

In accordance with our results, Javed et al. stated that thymol administration resulted in significant attenuation of oxidative stress, inflammation, and neuronal damage induced by Parkinson's disease in rats. These actions were attributed to inhibition of lipid peroxidation, besides the restoration of $\mathrm{GSH}$, catalase and superoxide dismutase antioxidant activates. Thymol administration significantly decreased the proinflammatory cytokines, viz. IL-6, IL-1 $\beta$, and TNF- $\alpha$ and inhibited glial cell activation [14]. In another study, thymol administration was associated with improved cognitive deficits due to up-regulation of the Nrf2 signaling pathway in mice [44]. Chamanara et al. reported significant NF-k $\beta$ signaling inhibition in acetic acid-induced inflammation in colon tissue in rats [45].

Further investigation is warranted to explore other potential pharmacological interventions to overcome MSG-induced neuro-toxic cerebral and hippocampal injury.

\section{Conclusion}

To summarize, from the current study, it can be concluded that thymol in the selected doses exhibited promising protective effects against MSG-induced 
neurotoxic cerebral and hippocampal injury in rats. The highert dose of thymol (800 mg/kg/day; p.o.) was foung more effective than the lower dose $(400 \mathrm{mg} / \mathrm{kg} / \mathrm{day}$ p.o.). Thymol's effects are mainly attributable to thymol's antioxidant and anti-inflammatory properties. These properties might be attributable to the up-regulation of the Nrf2 signaling pathway. The study elucidates the molecular mechanisms linking oxidative stress, inflammation, NF-k $\beta$ expression and Nrf2 pathway signaling underlying thymol's protection against MSG-induced neurotoxicity. The study also highlights GFAP expression's role in MSG-induced astrocyte injury of the cerebral cortex and hippocampus of rats and the promising protective effects of thymol in ameliorating astrocyte injury via reduction of elevated GFAP expression.

\section{Authors' Contributions}

All authors contributed to the study conception and design. Material preparation, data collection and analysis were performed by Rasha E. Mostafa and Abeer AA Salama. All histopathological and immunohistochemical experiments were conducted by Azza Hassan. The first draft of the manuscript was written by Rasha E. Mostafa and all authors commented on previous versions of the manuscript. All authors read and approved the final manuscript.

\section{Graphical-Abstract}

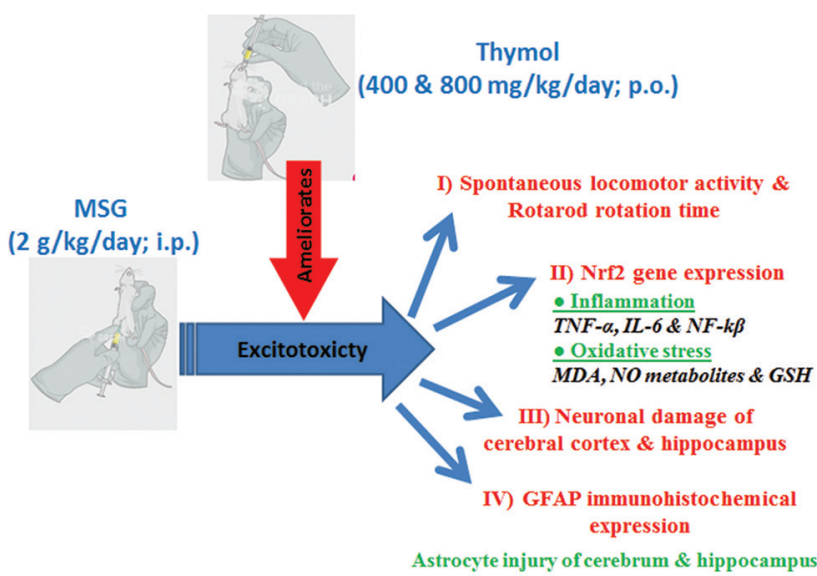

\section{References}

1. Onaolapo OJ, Onaolapo AY, Akanmu M, Gbola O. Evidence of alterations in brain structure and antioxidant status following "low-dose" monosodium glutamate ingestion. Pathophysiology. 2016;23(3):147-56. https://doi.org/10.1016/j. pathophys.2016.05.001

PMid:27312658

2. Walker R, Lupien JR. The safety evaluation of monosodium glutamate. J Nutr. 2000;130(4):1049S-52. https://doi. org/10.1093/jn/130.4.1049s

PMid:2731265810736380

3. Rotimi OA, Olayiwola I, Ademuyiwa O, Balogun EA. Effects of fibre-enriched diets on tissue lipid profiles of MSG obese rats. Food Chem Toxicol. 2012;50(11):4062-7. https://doi. org/10.1016/j.fct.2012.08.001

PMid:2731265822898616

4. Quines CB, Rosa SG, Da Rocha JT, Gai BM, Bortolatto CF, Duarte MM, et al. Monosodium glutamate, a food additive, induces depressive-like and anxiogenic-like behaviors in young rats. Life Sci. 2014;107(1-2):27-31. https://doi.org/10.1016/j. Ifs.2014.04.032

PMid:2731265824802127

5. Nagakannan P, Shivasharan B, Thippeswamy B, Veerapur V, Bansal P. Protective effect of hydroalcoholic extract of Mimusops elengi Linn. Flowers against middle cerebral artery occlusion induced brain injury in rats. J Ethnopharmacol. 2012;140(2):247-54. https://doi.org/10.1016/j.jep.2012.01.012 PMid:2731265822281124

6. Zanfirescu A, Ungurianu A, Tsatsakis AM, Nițulescu GM Kouretas D, Veskoukis $A$, et al. A review of the alleged health hazards of monosodium glutamate. Comprehens Rev Food Sci Food Saf. 2019;18(4):1111-34. https://doi. org/10.1111/1541-4337.12448

7. Shivasharan B, Nagakannan P, Thippeswamy B, Veerapur V. Protective effect of Calendula officinalis L. flowers against monosodium glutamate induced oxidative stress and excitotoxic brain damage in rats. Indian J Clin Biochem. 2013;28(3):292-8. https://doi.org/10.1007/s12291-012-0256-1 PMid:2731265824426226

8. Zarzuelo A, Crespo E. The medicinal and non-medicinal uses of thyme. In: Thyme: The Genus Thymus. Vol. 17. United States: CRC Press; 2002. p. 263-92.

9. Fachini-Queiroz FC, Kummer $R$, Estevao-Silva CF, Carvalho MD, Cunha JM, Grespan R, et al. Effects of thymol and carvacrol, constituents of Thymus vulgaris L. essential oil, on the inflammatory response. Evid Based Complement Alternat 2012;2012:657026. https://doi.org/10.1155/2012/657026 PMid:2731265822919415

10. Salehi B, Mishra AP, Shukla I, Sharifi-Rad M, Contreras DM, Segura-Carretero A, et al. Thymol, thyme, and other plant sources: Health and potential uses. Phytother Res. 2018;32(9):1688-706. https://doi.org/10.1002/ptr.6109 PMid:2731265829785774

11. Deb DD, Parimala G, Devi SS, Chakraborty T. Effect of thymol on peripheral blood mononuclear cell PBMC and acute promyelotic cancer cell line HL-60. Chem Biol Interact. 2011;193(1):97-106. https://doi.org/10.1016/j.cbi.2011.05.009 PMid:2731265821640085

12. Liang $\mathrm{D}$, Li F, Fu Y, Cao Y, Song $X$, Wang T, et al. Thymol inhibits LPS-stimulated inflammatory response via down-regulation of NF-KB and MAPK signaling pathways in mouse mammary epithelial cells. Inflammation. 2014;37(1):214-22. https://doi. org/10.1007/s10753-013-9732-x PMid:2731265824057926

13. Hashemipour H, Kermanshahi H, Golian A, Veldkamp T. Effect of thymol and carvacrol feed supplementation on performance, antioxidant enzyme activities, fatty acid composition, digestive enzyme activities, and immune response in broiler chickens. 
Poult Sci. 2013;92(8):2059-69. https://doi.org/10.3382/ ps.2012-02685

PMid:2731265823873553

14. Javed $\mathrm{H}$, Azimullah $\mathrm{S}$, Meeran M, Ansari SA, Ojha S. Neuroprotective effects of thymol, a dietary monoterpene against dopaminergic neurodegeneration in rotenone-induced rat model of Parkinson's disease. Int J Mol Sci. 2019;20(7):1538. https:// doi.org/10.3390/ijms20071538

PMid:2731265830934738

15. Kulkarni S. Experiments on isolated preparation. In: Hand Book of Experimental Pharmacology. Berlin, Germany: Springer; 1987. p. 3.

16. van den Berg $R$, Laman JD, van Meurs $M$, Hintzen $R Q$, Hoogenraad CC. Rotarod motor performance and advanced spinal cord lesion image analysis refine assessment of neurodegeneration in experimental autoimmune encephalomyelitis. J Neurosci Methods. 2016;262:66-76. https://doi.org/10.1016/j.jneumeth.2016.01.013

PMid:2731265826784021

17. Ruiz-Larrea MB, LealAM, LizaM, LacortM, de GrootH.Antioxidant effects of estradiol and 2-hydroxyestradiol on iron-induced lipid peroxidation of rat liver microsomes. Steroids. 1994;59(6):383-8. https://doi.org/10.1016/0039-128x(94)90006-x

PMid:273126587940617

18. Miranda KM, Espey MG, Wink DA. A rapid, simple spectrophotometric method for simultaneous detection of nitrate and nitrite. Nitric Oxide. 2001;5(1):62-71. https://doi. org/10.1006/niox.2000.0319

PMid:2731265811178938

19. Ellman GL. Tissue sulfhydryl groups. Arch Biochem Biophys. 1959;82(1):70-7. $\quad$ https://doi.org/10.1016/0003-9861(59) 90090-6

PMid:2731265813650640

20. Bulaj G, Kortemme T, Goldenberg DP. Ionization-reactivity relationships for cysteine thiols in polypeptides. Biochemistry. 1998;37(25):8965-72. https://doi.org/10.1021/bi973101r PMid:273126589636038

21. Brouckaert P, Libert C, Everaerdt B, Takahashi N, Cauwels A, Fiers W. Tumor necrosis factor, its receptors and the connection with interleukin 1 and interleukin 6 . Immunobiology. 1993;187(3-5):317-29. https://doi.org/10.1016/ s0171-2985(11)80347-5

PMid:273126588392490

22. Mostafa RE, Salama AA, Abdel-Rahman RF, Ogaly HA. Hepatoand neuro-protective influences of biopropolis on thioacetamideinduced acute hepatic encephalopathy in rats. Can J Physiol Pharmacol. 2016;95(5):539-47. https://doi.org/10.1139/ cjpp-2016-0433

PMid:2731265828177688

23. Bancroft J, Stevens A, Turner D. Theory and Practice of Histological Techniques. $4^{\text {th }}$ ed. New York Edinburgh, Madrid, Sanfrancisco: Churchill Living Stone; 1996. p. 20.

24. Khalil MN, Choucry MA, EI Senousy AS, Hassan A, El-Marasy SA, El Awdan SA, et al. Ambrosin, a potent NF- $\kappa \beta$ inhibitor, ameliorates lipopolysaccharide induced memory impairment, comparison to curcumin. PLoS One. 2019;14(7):e0219378. https://doi.org/10.1371/journal.pone.0219378 PMid:2731265831276550

25. Hassan NF, Nada SA, Hassan A, El-Ansary MR, Al-Shorbagy MY, Abdelsalam RM. Saroglitazar deactivates the hepatic LPS/ TLR4 signaling pathway and ameliorates adipocyte dysfunction in rats with high-fat emulsion/LPS model-induced non-alcoholic steatohepatitis. Inflammation. 2019;42(3):1056-1070. https:// doi.org/10.1007/s10753-019-00967-6

PMid:2731265830737662
26. Swamy AV, Patel N, Gadad P, Koti B, Patel U, Thippeswamy A, et al. Neuroprotective activity of pongamia pinnata in monosodium glutamate-induced neurotoxicity in rats. Indian J Pharm Sci. 2013;75(6):657.

PMid:2731265824591740

27. Sadek K, Abouzed T, Nasr S. Lycopene modulates cholinergic dysfunction, Bcl-2/Bax balance, and antioxidant enzymes gene transcripts in monosodium glutamate (E621) induced neurotoxicity in a rat model. Can J Physiol Pharmacol. 2016;94(4):394-401. https://doi.org/10.1139/cjpp-2015-0388 PMid:2731265826900785

28. Khalil RM, Khedr NF. Curcumin protects against monosodium glutamate neurotoxicity and decreasing NMDA2B and mGluR5 expression in rat hippocampus. Neurosignals. 2016;24(1):81-7. https://doi.org/10.1159/000442614

29. Vomhof-DeKrey EE, Picklo MJ Sr. The Nrf2-antioxidant response element pathway: A target for regulating energy metabolism. J Nutr Biochem. 2012;23(10):1201-6. https://doi. org/10.1016/j.jnutbio.2012.03.005

PMid:2731265822819548

30. ZhuW, Ding Y, Kong W, LiT, Chen H. Docosahexaenoic acid (DHA) provides neuroprotection in traumatic brain injury models via activating Nrf2-ARE signaling. Inflammation. 2018;41(4):118293. https://doi.org/10.1007/s10753-018-0765-z

PMid:2731265829663102

31. Sandberg M, Patil J, D'Angelo B, Weber SG, Mallard C. NRF2regulation in brain health and disease: Implication of cerebral inflammation. Neuropharmacology. 2014;79:298-306. https:// doi.org/10.1016/j.neuropharm.2013.11.004

PMid:2731265824262633

32. Nair S, Doh S, Chan J, Kong AN, Cai L. Regulatory potential for concerted modulation of Nrf2-and Nfkb1-mediated gene expression in inflammation and carcinogenesis. $\mathrm{Br} \mathrm{J}$ Cancer. 2008;99(12):2070-82. https://doi.org/10.1038/sj.bjc.6604703

33. Li X, Wang H, Gao Y, Li L, Tang C, Wen G, et al. Protective effects of quercetin on mitochondrial biogenesis in experimental traumatic brain injury via the Nrf2 signaling pathway. PLoS One. 2016;11(10):e0164237. https://doi.org/10.1371/journal. pone. 0164237 PMid:2731265827780244

34. Zhang L, Wang H, Fan Y, Gao Y, Li X, Hu Z, et al. Fucoxanthin provides neuroprotection in models of traumatic brain injury via the Nrf2-ARE and Nrf2-autophagy pathways. Sci Rep. 2017;7:46763. https://doi.org/10.1038/srep46763 PMid:2731265828429775

35. Cheng T, Wang W, Li Q, Han X, Xing J, Qi C, et al Cerebroprotection of flavanol (-)-epicatechin after traumatic brain injury via Nrf2-dependent and-independent pathways. Free Radic Biol Med. 2016;92:15-28. https://doi.org/10.1016/j. freeradbiomed.2015.12.027

PMid:2731265826724590

36. Wei CC, Kong YY, Li GQ, Guan YF, Wang P, Miao CY. Nicotinamide mononucleotide attenuates brain injury after intracerebral hemorrhage by activating $\mathrm{Nrf} / \mathrm{HO}-1$ signaling pathway. Sci Rep. 2017;7(1):1-13. https://doi.org/10.1038/ s41598-017-00851-z PMid:2731265828386082

37. Du J, He W, Zhang C, Wu J, Li Z, Wang M, et al. Pentamethylquercetin attenuates cardiac remodeling via activation of the sestrins/Keap1/Nrf2 pathway in MSG-induced obese mice. BioMed Res Int. 2020;2020:3243906. https://doi. org/10.1155/2020/3243906

38. Xu W, Mo J, Ocak U, Travis ZD, Enkhjargal B, Zhang T, et al. Activation of melanocortin 1 receptor attenuates early brain injury in a rat model of subarachnoid hemorrhage viathe 
suppression of neuroinflammation through AMPK/TBK1/NF-kB pathway in rats. Neurotherapeutics. 2020;17(1):294-308. https://doi.org/10.1007/s13311-019-00772-x

PMid:2731265831486022

39. Nurmasitoh T, Sari DC, Partadiredja G. The effects of black garlic on the working memory and pyramidal cell number of medial prefrontal cortex of rats exposed to monosodium glutamate. Drug Chem Toxicol. 2018;41(3):324-9. https://doi.org/10.1080/ 01480545.2017 .1414833

PMid:2731265829280389

40. Hashem HE, Safwat ME, Algaidi S. The effect of monosodium glutamate on the cerebellar cortex of male albino rats and the protective role of Vitamin C (histological and immunohistochemical study). J Mol Histol. 2012;43(2):179-86. https://doi.org/10.1007/s10735-011-9380-0

PMid:2731265822143495

41. Zaher EA. The possible neuroprotective effect of astaxanthin on monosodium glutamate and aspartame induced hippocampal changes in albino rats: (Histological and immuno-histochemical study). Egypt J Histol. 2020;43(3):684-701. https://doi. org/10.21608/ejh.2020.22609.1235

42. Priestley CM, Williamson EM, Wafford KA, Sattelle DB. Thymol, a constituent of thyme essential oil, is a positive allosteric modulator of human GABAA receptors and a homo-oligomeric GABA receptor from Drosophila melanogaster. $\mathrm{Br} J$ Pharmacol. 2003;140(8):1363-72. https://doi.org/10.1038/sj.bjp.0705542

PMid:2731265814623762

43. Sancheti J, Shaikh MF, Chaudhari R, Somani G, Patil S, Jain P, et al. Characterization of anticonvulsant and antiepileptogenic potential of thymol in various experimental models. Naunynschmiedebergs Arch Pharmacol. 2014;387(1):59-66. https://doi.org/10.1007/s00210-013-0917-5

PMid:2731265824065087

44. Li H, Qin T, Li M, Ma S. Thymol improves high-fat diet-induced cognitive deficits in mice via ameliorating brain insulin resistance and upregulating NRF2/HO-1 pathway. Metabolic Brain Dis. 2017;32(2):385-93. https://doi.org/10.1007/s11011-016-9921-z PMid:2731265827761760

45. Chamanara M, Abdollahi A, Rezayat SM, Ghazi-Khansari M, Dehpour A, Nassireslami E, et al. Thymol reduces acetic acidinduced inflammatory response through inhibition of NF-kB signaling pathway in rat colon tissue. Inflammopharmacology. 2019;27(6):1275-83. s10787-019-00583-8 https://doi.org/10.1007/ PMid:2731265830903350 